\title{
Office hysteroscopy, transvaginal ultrasound and endometrial histology: a comparison in infertile patients
}

\author{
Devleta Balić, Adem Balić \\ Clinic for human reproduction \\ "Dr. Balić" Tuzla \\ Bosnia and Herzegovina
}

Corresponding author:

Devleta Balic

Clinic for human reproduction

"Dr. Balić"

75000 Tuzla

Bosnia and Herzegovina

drbalic@bih.net.ba

Tel.: + 035257538

Fax: + 035260650

Received: 30 March 2011

Accepted: 21 April 2011

Copyright (C) 2011 by

Academy of Sciences and Arts

of Bosnia and Herzegovina.

E-mail for permission to publish:

amabih@anubih.ba

\begin{abstract}
Objective. To evaluate accuracy of transvaginal sonography (TVS) and hysteroscopy in detection of intrauterine pathology in infertile women. Subjects and methods. This retrospective study was conducted in 56 infertile women with abnormal transvaginal ultrasound findings of the uterine cavity which was performed during the midfollicular phase as a part of routine infertility workup. Hysteroscopy was performed between $6^{\text {th }}$ and $10^{\text {th }}$ day of cycle. Results. The mean age of the subjects was $31.9 \pm 4.0$. The most frequent ultrasound finding was endometrial polyp in $34(60.7 \%)$ patients, septate uterus in $8(14.3 \%)$ patients, submucosal myoma in $7(12.5 \%)$ patients, endometrial hyperplasia in 5 (8.9\%) patients and Syndroma Ascherman in $2(3.6 \%)$ patients. Hysteroscopy confirmed 20 (35.7\%) polyps, the same number of myomas, septate uterus and Syndroma Ascherman as detected by ultrasound, (7 (12.5\%), $8(14.3 \%)$ and $2(3.6 \%)$, respectively) and 19 (33.9\%) endometrial hyperplasia. In 46 women with histological excamination, the sensitivity of TVS and hysteroscopy in the diagnosis of endometrial polyps were identical - $100 \%$, while the specificity was higher in hysteroscopy than in TVS $(92.3 \%$ versus $56.4 \%, \mathrm{p}<0.001)$. The sensitivity of TVS in the diagnosis of endometrial hyperplasia was higher than that of hysteroscopy ( $86.4 \%$ versus $22.7 \%$, $\mathrm{p}<0.001)$, while specificity was identical, of $100 \%$. Accordance between hysteroscopy and histology was good $(\kappa=0.79)$, between ultrasound and hystology was moderete $(\kappa=0.59)$. Conclusion. Hysteroscopy appeared to be more reliable in diagnosis than TVS. The use of a high frequency ultrasound probe leads us to a lack of diagnostic clarity between endometrial polyps and hyperplasia.
\end{abstract}

Key words: Endometrium, Infertility, Ultrasound, Hysteroscopy, Hystology.

\section{Introduction}

Evaluation of the uterine cavity is the important part of examination of infertile women. Findings as a fibroids, polyps and Müllerian anomalies can impair fertility and result in poor outcome of pregnancy. Assessment of the endometrium is an important step in the management of women with diagnosed infertility. Abnormalities in the 
process of implantation could be the basis of many cases of unexplained infertility.

The first line diagnostic tool for uterine abnormalities is transvaginal sonography (TVS). It is an easy, fast and cheap technique that has became widely used. TVS has already proved to be a method with high reliability in diagnosing this pathology.

Hysteroscopy is the second step, which serves after an ultrasound examination as a form of screening. The advantage of hysteroscopy is that we diagnose and treat the changes we notice at the same time. Over recent years hysteroscopy is being increasingly used in out-patient facilities which alongside the standard advantages of hysteroscopy also provide greater comfort for the patients, since it excludes the need to stay in hospital and decreases the time of treatment, but also the time needed to prepare the patient for further procedures, e.g. medically assisted conception $(1,2,3)$.

The aim of this study was to evaluate accuracy of transvaginal ultrasound and hysteroscopy in detection of intrauterine pathology in infertile women.

\section{Patients and methods}

This retrospective study was conducted from July 2008 to December 2010 in 56 infertile women. At the time of the study all patients had a history of primary or secondary infertility of one-year duration. The inclusion criteria was abnormal transvaginal ultrasound findings of uterine cavity which was performed as a part of routine infertility workup afterwards every women was underwent the office hysteroscopy procedure in the same centre.

\section{Ultrasound evaluation}

TVS was performed during the midfollicular phase of the cycle ( $6^{\text {th }}$ to $10^{\text {th }}$ day) using an Volusion 730 expert (General Electric,
New York, USA) equipped with a $9.0 \mathrm{MHz}$ transvaginal probe. The endometrial cavity contours and echo patterns of the endometrium were evaluated for irregularities in both the transverse plane and the long axis. All examinations were performed by the same operator.

\section{Hysteroscopy technique}

Hysteroscopy was performed in the early follicular phase (6 to 10. day) using a $9 \mathrm{~mm}$ continuous-flow operative office hysteroscope based on a $4 \mathrm{~mm}$ rod lens scope (Karl Storz, Tuttlingen, Germany). With intravenous anaesthesia with Diprivan cervical dilatation was performed up to Hegar 9.5. The uterine cavity was distended by normal saline solution and intra-uterine pressure was controlled by an irrigation-suction device (Varioflow, Ljubljana, Slovenia). Intrauterine pressure was set around $30 \mathrm{mmHg}$, resulting in a balance of the irrigation flow of around $200 \mathrm{ml} /$ minute and a vacuum of 0.1 bars. Endometrial specimens were obtained by $5 \mathrm{Fr}$ crocodile biopsy forceps (Karl Storz). Endometrial polyps, myomas and septa were treated utilising the operative facilities of the hysteroscope with Versapoint eletrodes (Johnson and Johnson, New Yersy, USA).

Whenever a lesion was found by hysteroscopy, except in the case of septate uterus and Syndroma Ascherman, it was hysteroscopically excised during the same procedure, fixed in formalin and sent for histological examination.

\section{Statistical analysis}

Numerical data are presented as mean \pm standard deviation, while categorical data are expressed as proportions. The diagnostic accuracy characteristics as sensitivity, specificity, positive predictive value (PPV) and negative predictive value (NPV) for both 
hysteroscopy and TVS were calculated using histological diagnosis as the gold standard. Differences between proportions were tested by the chi-squared test. The level of agreement between methods was measured by Kappa test. A p value less than 0.05 was considered statistically significant. Data were analyzed using the PASW 18 software (SPSS Inc., Chicago, IL, USA).

\section{Results}

In this retrospective study 56 infertile patients were included with abnormal ultrasound appearance of the uterine cavity. The mean age ( \pm standard deviation) of the patients was $31.9 \pm 4.0$. The distribution of the various abnormalities detected by ultrasound and hysteroscopy is reported in Table 1. The most frequent ultrasound finding was endometrial polyp in $34(60.7 \%)$ patients, then septate uterus in $8(14.3 \%)$ patients, submucosal myoma in 7 (12.5\%) patients, endometrial hyperplasia in 5 (8.9\%) patients and Syndroma Ascherman in 2 (3.6\%) patients.

Hysteroscopy confirmed 20 (35.7\%) endometrial polyps, the same number of myomas, septate uterus and Syndroma Ascherman was detected by ultrasound [7 (12.5\%), $8(14.3 \%)$ and $2(3.6 \%)$, respectively, and 19 (33.9\%)] endometrial hyperplasia. There were no failed hysteroscopic procedures.

In 46 women, the histological examination of endometrial specimen was performed. In the diagnosis of submucosal myoma, all measured diagnostic accuracy characteristics, according to histological examination, for hysteroscopy and TVS were identical (Table 2). In the diagnosis of en-

Table 1 The incidence of different abnormalities diagnosed by hysteroscopy, ultrasonography and histology in 56 infertile women

\begin{tabular}{lllllll}
\hline \multirow{2}{*}{ Endouterine abnormalities } & \multicolumn{2}{l}{ Hysteroscopy } & \multicolumn{3}{l}{ TVS } & \multicolumn{2}{l}{ Histology } \\
\cline { 2 - 7 } & $\mathrm{N}$ & $\%$ & $\mathrm{~N}$ & $\%$ & $\mathrm{~N}$ & $\%$ \\
\hline Polyp & 20 & 35.7 & 34 & 60.7 & 17 & 37.0 \\
Submucosal myoma & 7 & 12.5 & 7 & 12.5 & 7 & 15.2 \\
Syndroma Ascherman & 2 & 3.6 & 2 & 3.6 & 0 & 0 \\
Septate uterus & 8 & 14.3 & 8 & 14.3 & 0 & 0 \\
Endometrial hyperplasia & 19 & 33.9 & 5 & 8.9 & 22 & 47.8 \\
\hline Total & 56 & 100 & 56 & 100 & 46 & 100 \\
\hline
\end{tabular}

*Transvaginal sonography

Table 2 Sensitivity and specificity of ultrasonography and hysteroscopy, based on histology in 46 infertile women

\begin{tabular}{lllll}
\hline Diagnostic method & Sensitivity (\%) & PPV*(\%) $^{*}$ & Specificity (\%) & NPV $^{\text {s }}(\%)$ \\
\hline Ultrasonography (polyp) & 100 & 50 & 56.4 & 100 \\
Ultrasonography (myoma) & 100 & 100 & 100 & 100 \\
Ultrasonography (endometrial hyperplasia) & 22.7 & 100 & 100 & 66.7 \\
Hysteroscopy (polyp) & 100 & 85 & 92.3 & 100 \\
Hysteroscopy (myoma) & 100 & 100 & 100 & 100 \\
Hysteroscopy (endometrial hyperplasia) & 86.4 & 100 & 100 & 91.9 \\
\hline
\end{tabular}

*Positive predictive value; ${ }^{\S}$ Negative predictive value 
dometrial polyps, the sensitivity of hysteroscopy and TVS were of 100\%, both. However, the specificity and PPV were higher in hysteroscopy than in TVS $(92.3 \%$ versus $56.4 \%, \chi^{2}=11.36, \mathrm{p}<0.001$, and $85 \%$ versus $50 \%, \chi^{2}=5.20, \mathrm{p}=0.023$, respectively). In the diagnosis of endometrial hyperplasia, the sensitivity and NPV of hysteroscopy was higher than that of TVS $(86.4 \%$ versus $22.7 \%, \chi^{2}=15.49, \mathrm{p}<0.001$, and $91.9 \%$ versus $66.7 \%, \chi^{2}=6.40, \mathrm{p}=0.011$, respectively), while specificity was the same (of $100 \%$ in both). Accordance between hysteroscopy and histology was good ( $\kappa=0.79,95 \%$ CI: $0.67,0.91$ ) and between ultrasound and hystology was moderete ( $\kappa=0.59,95 \%$ CI: $0.44,0.75)$.

In the diagnosis of endometrial polyps and hyperplasia, the concordance between hysteroscopy and histology (0.93) was significantly higher than the concordance between TVS and histology (0.63) ( $\chi 2=12.52$, $\mathrm{p}<0.001)$. However, in the diagnosis of submucosal myoma, the concordance of hysteroscopy and TVS with histology was identical ( concordance index $=1$ ).

\section{Discussion}

Intrauterine pathology such as polyps, submucosal myoma and uterine septa are relatively common and may impair fertility. Traditionally, the assessment of the uterine cavity for the basic infertility work-up has been performed by TVS and hysteroscopy. In the last decade, improvements in ultrasound and hysteroscopy technologies have changed the diagnostic approach. On the one hand the introduction of a high-frequency transvaginal probe increases the possibility of diagnosis, and on the other hand the introduction of "office hysteroscopy" enables direct visualisation of the cervix and the uterine cavity and at the same time the possibility of treating the abnormalities diagnosed. The results of this study whith sensitivity of $100 \%$ and specificity of $100 \%$ in diagnosis of submucosal myoma and uterine septa confirmed the results of other studies according to hysteroscopy as the gold standard in the diagnosis of endouterine pathologies, such as submucosal myomas and anomalies of the uterine cavity $(2,4)$.

In this study the endometrial polyps and hyperplasia are the most frequent findings of endouterine pathologies. But we noticed differences between TVS and hysteroscopy in their diagnostic accuracy: lower specificity in the diagnosis of polyps (56\% versus $92 \%$ ) and lower sensitivity in the diagnosis of hyperplasia (23\% versus $86 \%$ ) with TVS in comparison to hysteroscopy. In the analysis of the results we found that in those cases in which hysteroscopy and histology did not confirm the existence of an endometrial polyp, it was actually a case of endometrial hyperplasia, but we had diagnosed it as an endometrial polyp by TVS. Mukhopadhayay et al. (5) compard TVS, hysteroscopy and histology in perimenopausal women with abnormal uterine bleeding and found similar results in sensitivity and specificity of ultrasound in diagnosis of polyps and endometrial hyperplasia as are results of our study. Shalev et al. (6) compared TVS and hysteroscopy findings in infertile patients and found disagreement between methods in diagnosis of polyps end endouterine synechia.

Since the ultrasound examinations were performed by a single operator on the same ultrasound apparatus, we tried to analyse and find the reasons for this discrepancy between ultrasound and hysteroscopy diagnosis. We believe that a possible reason lies precisely in the use of a high frequency probe and images with better resolution, which show changes in the structure of the endometrial hyperplasia clearly. So, for example echogenic zones are shown as small polyps in the surrounding less echogenic tissue. Looking for data in the literature, we came across similar results obtained by 
authors following changes caused to the endometrium in women who take Tamoxifen. In those cases too TVS proved to be less reliable than hysteroscopy (7) as in the postmenopausal women when endometrium appears as a normal $(8,9)$.

The question arose whether this in fact had any clinical significance when both endometrial hyperplasia and polyps are conditions which require treatment in infertile patients, and indicate hysteroscopy for further diagnosis and treatment.

This could lead us to think about the fact that advances in ultrasonography technology by introducing a high frequency probe improve diagnostic possibilities but impose the need to set new diagnostic criteria related to the structure of endometrial echo structures.

If we take in consideration that ultrasound and hysteroscopy was done by the same observer we could think about his subjectivity as a limitation of the study (10). The second limitation is a small number of participants.

\section{Conclusion}

Hysteroscopy appeared to be more reliable in diagnosis than TVS and offers the possibility of simultaneous diagnosis treatment of endouterine pathologies in infertile women. Introduction of a high frequency probe leads us to a lack of diagnostic clarity between endometrial polyps and endometrial hyperplasia.

Authors' contributions: Conception and design: DB; Acquisition, analysis and interpretation of data: DB and AB; Drafting the article: DB; Revising it critically for important intellectual content: $\mathrm{DB}$ and $\mathrm{AB}$.

Conflict of interest: The authors declare that they have no conflict of interest. This study was not sponsored by any external organisation.

\section{References}

1. Ozturk E, Ugur MG, Balat O, Kutlar I, Dikensoy E, Cebesoy B. An analysis of hysteroscopy experience over a seven-year period. Clin Exp Obstet Gynecol. 2010;37(2):150-1.

2. Ait Benkaddour Y, Gervaise A, Fernandez H. Which is the method of choice for evaluating uterine cavity in infertility workup? Gynecol Obstet Biol Reprod. 2010;39(8):606-13.

3. Bosteels J, Weyers S, Puttemans P, Panayotidis C, Van Herendael B, Gomel V at al. The effectiveness of hysteroscopy in improving pregnancy rates in subfertile women without other gynaecological symptoms: a systematic review. Hum Reprod Update. 2010;16(1):1-11.

4. Loverro G, Nappi L, Vicino M, Carriero C, Vimercati A, Selvaggi L. Uterine cavity assessment in infertile women: comparison of transvaginal sonography and hysteroscopy. Eur J Obstet Gynecol Reprod Biol. 2001;100(1):67-71.

5. Mukhopadhayay S, Bhattacharyya SK, Ganguly RP, Patra KK, Bhattacharya N, Barman SC. Comparative evaluation of perimenopausal abnormal uterine bleeding by transvaginal sonography, hysteroscopy and endometrial biopsy. J Indian Med Assoc. 2007;105(11):624.

6. Shalev J, Meizner I, Bar-Hava I, Dicker D, Mashiach R, Ben-Rafael Z. Predictive value of transvaginal sonography performed before routine diagnostic hysteroscopy for evaluation of infertility. Fertil Steril. 2000;73(2):412-7.

7. Liedman R, Lindahl B, Andolf E, Willen R, Ingvar C, Ranstam J. Disaccordance between estimation of endometrial thickness as measured by transvaginal ultrasound compared with hysteroscopy and directed biopsy in breast cancer patients treated with tamoxifen. Anticancer Res. 2000;20(6C):4889-91.

8. Kasraeian M, Asadi N, Ghaffarpasand F, Karimi AA.Value of transvaginal ultrasonography in endometrial evaluation of non-bleeding postmenopausal women. Climacteric. 2011;14(1):126-31.

9. Dreisler E, Sorensen SS, Ibsen PH, Lose G. Value of endometrial thickness measurement for diagnosing focal intrauterine pathology in women without abnormal uterine bleeding. Ultrasound Obstet Gynecol. 2009;33(3):344-8.

10. Kasius JC, Broekmans FJ, Veersema S, Eijkemans MJ, van Santbrink EJ, Devroey et al. Observer agreement in the evaluation of the uterine cavity by hysteroscopy prior to in vitro fertilization. Hum Reprod. 2011;26(4):801-7. 